\title{
Ressonâncias husserlianas na obra Lógica do sentido de Gilles Deleuze ${ }^{1}$
}

\section{Husserl's resonances in the composition Logic of Sense of Gilles Deleuze}

\section{Alex Fabiano Correia Jardim}

Doutor em Filosofia pela Universidade Federal de São Carlos (UFSCar), com estágio no exterior pela Université de Paris I - Panthéon Sorbonne, professor do Departamento de Filosofia e do Programa de Mestrado em Estudos Literários da Universidade Estadual de Montes Claros (UNIMONTE), coordenador do Grupo de Pesquisa em Filosofia do Departamento de Filosofia da Universidade Estadual de Montes Claros (UNIMONTE), Montes Claros, MG - Brasil, e-mail: alex.jardim38@hotmail.com

\section{Resumo}

Discutiremos, a partir dos textos Lógica do sentido e Diferença e repetição de Gilles Deleuze, duas perspectivas: por um lado, uma crítica estabelecida por Deleuze ao conceito de transcendência e transcendental à fenomenologia de Husserl, e por outro lado, apontaremos a importância de Husserl para Deleuze, em especial, a conversação filosófica possível entre eles construída na obra Lógica do sentido. Se por um lado, para Husserl

1 Dedicado ao professor Bento Prado de Almeida Ferraz Júnior. 
a fenomenologia pensa a existência submetida às estruturas constitutivas da transcendência como camada fundamental da atividade transcendental sob a forma de uma gênese. Por outro lado, para Deleuze, não há qualquer necessidade de um pressuposto (genético) ao pensamento na figura de um cogito (sujeito). Em lugar de se perguntar sobre a gênese do pensamento, Deleuze problematiza "o que significa pensar?", afastando-se de uma imagem dogmática do pensamento. Mas Deleuze demonstra em vários momentos no texto Lógica do sentido a contribuição de Husserl quando este pensa o problema do "expresso", do "noema" e do "sentido", todos enquanto "verdadeiros acontecimentos". Tais questões para Deleuze impõem um limite ao ego transcendental, não reduzindo o pensamento ao jogo representacional do sujeito.

Palavras-chave: Transcendência. Transcendental. Fenomenologia. Imanência. Empirismo transcendental.

\section{Abstract}

Based on Deleuze's texts Logic of sense and Difference and repetition we will discuss two perspectives: on one hand, we'll have estabilished in Deleuze criticism, the concept of transcendence and transcendental to Husserl's phenomenology; in another hand we'll consider Husserl's importance to Deleuze, especially the possibility of a philosophical conversation constructed by them in the work Logic of sense. On one hand, Husserl's phenomenology thinks the submitted existence to the constitutives structures of transcendence as a fundamental layer of transcendental activity in the form of a genesis. To Deleuze, in another hand, there isn't any necessity of a (genetic) assumption to the thought on the picture of a cogito (subject). If Husserl's transcendence is the result of a constituent intentionality, to Deleuze it would only amount to a philosophy of representation as consistent exercise of the faculties. Instead of wonder about the genesis of thought, Deleuze problematizes "wich means thinking?", moving away from a dogmatic image of thought. In Deleuze this "meeting" is not priveleged by any representational perspective, but for a paradoxical instance or a disjunction.But it isn't only of differences that this dialogue survives, after all, Deleuze demonstrates in several moments in the text Logic of sense, Husserl's contribution when he thinks the problem of "express", the "noema" (transcendental dimension of na object) and the "sense", all of them as "true events". Such issues calls Deleuze's attention, because they 
impose a limit to transcendental ego, not reducing the reducing the thought representational play of the subject.

Keywords: Transcendental. Phenomenology. Immanence. Transcendental empiricism.

\section{Introdução}

Em seus textos, Gilles Deleuze demonstrou simpatia por vários filósofos, mas, diante de tantos autores que perpassam os escritos de Deleuze, teremos em Husserl (1859-1938) um tipo de "fantasma". Husserl ocupará um papel de destaque nas discussões desenvolvidas por Deleuze a partir de 1969, em sua obra Lógica do sentido (utilizaremos a tradução brasileira da obra referente ao ano 2000). É a partir da leitura de Lógica do sentido que descobrimos que há uma "abertura" para pensarmos os problemas discutidos por Husserl: a ideia do que é a filosofia, o pensamento e a crença na ideia de um indivíduo constituinte do mundo e a noção de transcendental. ${ }^{2}$ Para, de alguma forma, tentar justificar a escolha dessa dramaturgia teórica (tendo Deleuze e Husserl como protagonistas), a introdução de O que é a Filosofia (1992) nos serviria de suporte. Precisaríamos não só de um campo próprio, mas de personagens conceituais que, necessariamente, não seriam "nossos amigos". Se essas são as condições de possibilidade do pensar, por que não poderíamos dizer o mesmo dos "nossos rivais"? Daqueles que incitam o jogo da disputa? Essa tensão entre a admiração e a desconfiança é que marcará a presença de Husserl na obra de Deleuze. Se Deleuze não unifica o seu pensamento com o de Husserl e busca os desvios necessários de uma geografia conceitual que mais lhe convém, isso não o torna menos competente; pelo contrário, mostra o mérito de seu pensamento e sua ardilosa qualidade por afastar-se de uma hermenêutica e aproximar-se de uma experimentação. Se Husserl é instituído

2 Ressaltamos aqui que foi escrito na França um texto do Alain Beaulieu e publicado pela editora Vrin, intitulado Deleuze et la phénoménologie. Observamos também um texto chamado Échos husserliens dans l'oeuvre de G. Deleuze, escrito por Francisco José Martinez e publicado pela Vrin (1988) sob a coordenação de Pierre Verstraeten e Isabelle Stengers, numa coletânea de textos que trata do pensamento de Gilles Deleuze.

Rev. Filos., Aurora, Curitiba, v. 22, n. 31, p. 391-408, jul./dez. 2010 
num jogo ambíguo de amizade e rivalidade, isso apenas ressalta a potência de um pensamento como o de Gilles Deleuze.

\section{Deleuze e a proposta de desmontagem da maquinaria husserliana}

O que se estabelece entre Husserl e Deleuze são as problemáticas da constituição do sujeito transcendental e o silêncio daquilo que foi sendo edificado no decorrer do pensamento moderno: o sujeito e a consciência em favor de sua constituição no interior dos "planos de imanência", não mais como substância, mas modos de individuação. Na verdade, o pensamento de Deleuze tenta realizar uma desmontagem da maquinaria husserliana e, nessa empreitada, alguns conceitos pensados por Husserl recebem plena aceitação de Deleuze, surpreendendo-nos bastante a profunda admiração de Deleuze pelas descobertas husserlianas, como ele mesmo expressa em Lógica do sentido. Na Terceira Série "Da proposição", de sua obra Lógica do sentido, Deleuze faz uma notável observação (e, por que não dizer, polêmica observação) acerca do pensamento de Husserl no que diz respeito à problemática do objeto e do sentido, vinculando-o corajosamente às questões do empirismo transcendental. As observações deleuzeanas nos auxiliam na afirmação de sua simpatia, pelo menos, em alguns momentos, pelas questões levantadas por E. Husserl. Leiamos com atenção:

[...] A lógica do sentido é toda inspirada de empirismo, mas, precisamente, não há senão o empirismo que saiba ultrapassar as dimensões experimentais do visível, sem cair nas Idéias e encurralar, invocar, talvez produzir um fantasma no limite extremo de uma experiência alongada, desdobrada. Esta dimensão última chamada por Husserl expressão: se distingue da designação, da manifestação, da demonstração. O sentido é o expresso. [...] Quando Husserl se interroga, por exemplo, sobre o "noema perceptivo" ou o "sentido da percepção", ele o distingue ao mesmo tempo do objeto físico, do vivido psicológico, das representações mentais e dos conceitos lógicos. Ele o apresenta como um impassível, um incorporal, sem existência física nem mental, que não age nem padece, puro resultado, pura "aparência": a árvore real (o designado) pode queimar, ser sujeito ou objeto de ação, entrar em misturas; não o noema da árvore. Há muitos noemas ou sentidos para um só e mesmo designado: estrela da noite e estrela da manhã são dois noemas, isto é, duas maneiras pelas quais um mesmo designado se apresenta em expressões. Mas, nestas condições, quando Husserl diz que o noema é o 
percebido tal como aparece em uma apresentação, o "percebido como tal" ou a aparência, não devemos compreender que se trata de um dado sensível ou de uma qualidade, mas, ao contrário, de uma unidade ideal objetiva como correlato intencional do ato de percepção. Um noema qualquer não é dado em uma percepção (nem em uma lembrança ou em uma imagem), ele tem um estatuto completamente diferente que consiste em não existir fora da proposição que o exprime, proposição perceptiva, imaginativa, de lembrança ou de representação. Do verde como cor sensível ou qualidade, distinguimos o "verdejar" como por noemática ou atributo. A árvore verdeja, não é isto, finalmente, o sentido de cor da árvore e a árvore arvorifica, seu sentido global? O noema será outra coisa além de um acontecimento puro, o acontecimento de árvore (embora Husserl assim não fale, por razões terminológicas)? E o que ele chama de aparência, é um efeito de superfície? Entre os noemas de um mesmo objeto ou mesmo de objetos diferentes se elaboram laços complexos análogos aos que a dialética estóica estabelece entre os acontecimentos. Seria a fenomenologia esta ciência rigorosa dos efeitos de superfície? (DELEUZE, 2000, p. 22).

A partir desta citação anterior, não seria exagero afirmarmos que a fenomenologia, salvo seus limites, seria um tipo de empirismo transcendental. Santos (1973, p. 269) nos dá uma pista sobre tal possibilidade, corroborando com Gilles Deleuze. Vejamos:

\begin{abstract}
A fidelidade ao dado, à presença, é uma constante na obra de Husserl. O pensamento no mais elevado sentido será sempre o pensamento significativo sancionado pela presença do fenômeno. A dialética da presença comandará o ideal de rigor e indicará o caminho à análise intencional: o esforço de tornar patente o que é latente, de evidenciar o opaco, confunde-se com o esforço de tornar manifesta a presença da estrutura que comanda o discurso e que é no entanto tão fugidia. A sombra do discurso torna-se luz, phainomenon.
\end{abstract}

Sabendo-se que, a fenomenologia nos remete à ideia de um eu e de uma síntese originária, a conversação que será estabelecida terá como referência a crítica e a recepção de Husserl como pensador da consciência ou de uma filosofia do sujeito no pensamento de Gilles Deleuze. Fazemos a seguinte observação:

- naquilo que os diferencia acerca do problema do sujeito, falta a Husserl, segundo Deleuze, levar adiante a radicalidade de seu pensamento, 
experimentar um tipo de violência que força a pensar e que, por consequência, destruiria uma "imagem dogmática do pensamento" calcado na ideia de identidade e de uma substância pensante.

Segundo Husserl: tudo o que há é subjetivo como se todo o movimento e dinamismo fossem determinados pelo sujeito. Nesse sentido, o ponto de ruptura para Deleuze é que Husserl elabora sua filosofia transcendental a partir do entendimento de que é na consciência pura que se encontra o ser absoluto doador de sentido a toda transcendência. É essa intenção que dá sentido ao mundo, como se o "eu" fosse uma flecha do tempo, partindo do heterogêneo ao homogêneo, na busca de um equilíbrio - entre consciência transcendental e objeto - corroborada pela evidência do vivido imanente.

Há segundo Deleuze, um problema quando Husserl se envereda na filosofia do sujeito ou da consciência transcendental. E o problema tem um nome, a idéia de pressuposto para a filosofia. Deleuze trata da subjetividade sem utilizar qualquer tipo de pressuposto ou fundamento metafísico, como a crença na existência de um ego transcendental. Nesse caminho, Husserl parece nos deixar claro que o pensamento é quase uma naturalidade. Sob o nome de intencionalidade, é promulgado um direito ao conhecimento, significando para o pensamento uma tranquilidade, um apaziguamento.

Por mais que Husserl proporcione, com a sua ideia de Epoché e Redução, uma eliminação de todo e qualquer pressuposto, a suspensão da tese do mundo como determinante para o conhecimento, ele continuará preso nessa atitude de purificação filosófica. Ele somente mudará de foco a atenção: não interessa mais o "mundo dos fatos" para iniciarmos o pensamento. Esse "começar filosófico" é substituído pela consciência transcendental. Daí, Husserl não se livra de maneira alguma dos pressupostos para o exercício do pensamento. Para Deleuze (1988), contrariamente, "não há nada que nos garanta uma fundamentação sólida e segura para o começar filosófico". Sendo assim, podemos afirmar que pressuposto e gênese são os problemas com os quais Husserl se depara. Todo seu esforço, desde $A$ ideia de fenomenologia ${ }^{3}$ (1907) - resultado de conferência na cidade de Göttingen entre 26 de abril e 2 de maio de 1907 -, passando pela Filosofia como ciência do rigor (1911), até Ideias I (1913) e Meditações cartesianas (1929), se constituiu em fazer ruir o que denominaríamos de "falsa gênese" (inicialmente, pensada como "falsa"),

3 Utilizaremos a tradução portuguesa: HUSSERL, E. A ideia de fenomenologia. Tradução de Artur Mourão. Lisboa: Edições 70, 1989. 
isto é, como uma crítica ao reino do psíquico ou da ciência natural, ambas, antifilosóficas. $\mathrm{Na}$ verdade, quando falamos de falsa gênese, cometemos um "erro", pois a sua falsidade se institui na verdade como uma "gênese passiva", comprometendo a ideia anterior de "falsidade". Por outro lado, a noção de pressuposto em Husserl não é tão simples de ser dissuadida, como pretendia o próprio filósofo. Nem mesmo a "epoché" e a "redução" operadas pelo esquematismo husserliano nos convencem de uma verdadeira e eficaz crítica aos pressupostos, pois estes, se não são mais propiciados pelos "dados sensíveis", o são na "imagem" de uma consciência noética.

Em sua obra $A$ ideia da fenomenologia (1989), Husserl aborda na Primeira e Segunda Lições sobre o problema do conhecimento e do pensamento, uma vez que ele tratará do verdadeiro pensamento como uma atitude filosófica, e afirma que se trata "dos mais profundos e mais difíceis problemas, em suma, do problema da possibilidade do conhecimento" (HUSSERL, 1907). Tal proposição nos remeterá à necessidade de um princípio universal que possibilite o estabelecimento de um pressuposto.

Se nada lhe é permitido pressupor, como previamente dado, deve então começar por algum conhecimento, que ela não toma mais de outro lado, mas antes a si mesma o dá, que ela (a redução) própria põe como conhecimento primeiro. A este primeiro conhecimento não é permitido conter absolutamente nada de obscuridade e incerteza que normalmente conferem aos conhecimentos o caráter de enigmático, do problemático, o qual nos lança por fim em tal perplexidade que somos induzidos a dizer que o conhecimento em geral é um problema, uma coisa incompreensível, carente de elucidação, duvidosa quanto à sua pretensão (HUSSERL, 1989, p. 53-54, grifo nosso).

Parece-nos bem clara a proposta de Husserl na defesa de um pressuposto como condição para o conhecimento. Na citação, ele indica um "puro ver enquanto dado absoluto", do qual não podemos duvidar. Lembrando Deleuze, é o mesmo que afirmarmos uma "boa vontade" natural que nos move no mundo e nos faz produzir ciência e filosofia. É o pressuposto do Eu Penso - Eu Sou como estatuto e dado absoluto. Do contrário, observaremos em Deleuze não uma pergunta acerca das condições do conhecimento, mas a interrogação deleuziana seria “sobre o que significa pensar?". E tal questão não se restringe a igualar pensamento e verdade.

Deleuze dá o nome de "imagem do pensamento" a imagem da verdade, formada por elementos pressupostos e contra uma imagem dogmática 
do pensamento Deleuze pensará o problema do paradoxo, isto é, não existe uma identidade no pensamento que garanta uma relação de docilidade entre sujeito e objeto na busca de uma verdade apodídica. Na Décima Segunda Série de Lógica do sentido, ele chama a atenção a respeito da ideia de paradoxo e de como este conceito pode provocar fraturas na maquinaria husserliana:

Os paradoxos de significação são essencialmente o conjunto anormal (que se compreende como elemento ou que compreende elementos de diferentes tipos) e o elemento rebelde (que faz parte de um conjunto cuja existência ele pressupõe e pertence aos dois subconjuntos que determina). Os paradoxos de sentido são essencialmente a subdivisão ao infinito (sempre passado-futuro e jamais presente) e a distribuição nômade (repartir-se em um espaço aberto ao invés de repartir um espaço fechado). Mas, de qualquer maneira, têm por característica o fato de ir em dois sentidos ao mesmo tempo e tornar impossível uma identificação [...] (DELEUZE, 2000, p. 77-78).

A docilidade é substituída pela ideia de violência e má-vontade como aquelas que destituirão completamente todos os pressupostos para o filosofar. Como aponta José Gil (2000) no prefácio de Diferença e repetição, "Deleuze pretende nos desembaraçar da doxa, recomeçar tudo do zero". ${ }^{4}$

A partir disso, será que o problema que levantamos anteriormente sobre o pensamento husserliano enquanto representação e bom senso não encontrariam agora a sua justificativa? Expliquemo-nos melhor: mesmo Deleuze não citando Husserl diretamente, ele não poderia dizer que a filosofia de Husserl permanece fiel e aprisionada num tipo de crença na forma-eu ou numa conformidade entre consciência e objeto? Enfim, a fenomenologia husserliana não se liberta dos pressupostos subjetivos.

Nesta direção, seguem-se dois conceitos que em Husserl exemplificam esta afirmativa: intencionalidade e redução, simultâneos aos conceitos de identidade e semelhança, traduzidos aqui na noção de "evidência", que ele tanto debate nas Meditações cartesianas, em especial na Terceira Meditação: $\S$ 24: "A evidência como dado originário. Suas variantes". Vejamos também o $\S 26$ : "A realidade considerada como correlata da verificação evidente".

[...] Sabemos também que só podemos estar seguros do ser real por meio da síntese de confirmação verificadora, a única que nos apresenta a realidade

${ }^{4}$ GIL, J. Prefácio. In. DELEUZE, G. Diferença e repetição. Lisboa: Relógio D’Água, 2000. p. 9. 
verdadeira. Fica claro que só se pode extrair a noção da verdade ou da realidade verdadeira dos objetos a partir da evidência; é graças apenas a ela que a designação de um objeto como realmente existente, verdadeiro, legitimamente válido - seja qual for sua forma ou espécie - adquire para nós um sentido, e o mesmo se dá em relação a todas as determinações que para nós - lhe pertence verdadeiramente. Qualquer justificação provém da evidência e, em conseqüência, encontra sua fonte em nossa própria subjetividade transcendental (HUSSERL, 2001, p. 76).

Pela intencionalidade e evidência, a identidade do objeto exige como fundamento unidade de um sujeito pensante. Deixar claro isso é o que pretende Husserl ao tratar do problema concernente "à origem", ou à gênese. ${ }^{5}$

Em Husserl, teremos uma subjetividade transcendental que não só concorda com o objeto, mas doa sentido como constituição transcendental do objeto. É o que Deleuze chama de concordia facultatum.

Simultaneamente, a recognição exige o princípio subjetivo da colaboração das faculdades para "todo mundo", isto é, um senso comum como concórdia facultatum; e, para o filósofo, a forma da identidade do objeto exige um fundamento na unidade de um sujeito pensante do qual todas as outras faculdades devem ser modos. É este o sentido do Cogito como começo: ele exprime a unidade de todas as faculdades no sujeito; exprime, pois, a possibilidade de todas as faculdades se referirem a uma forma de objeto que reflita a identidade subjetiva; ele dá, assim, um conceito filosófico ao pressuposto do senso comum, ele é o senso comum tornado filosófico (DELEUZE, 1988, p. 195).

E qual seria o elemento que provocaria a torção nessa representação?

[...] O que é primeiro no pensamento é o arrombamento, a violência, é o inimigo, e nada supõe a Filosofia; tudo parte de uma misosofia. Não contemos com o pensamento para fundar a necessidade relativa do que ele pensa; contemos, ao contrário, com a contingência de um encontro com aquilo que força a pensar, a fim de elevar e instalar a necessidade absoluta de um ato

5 Em Expérience et Jugement (1970 - trad. Francesa, 1. ed.), na “Introdução", Husserl afirma: "Nossa tarefa é então, uma elucidação da essência do julgamento predicativo através de uma enquête, portanto sobre sua origem" HUSSERL (1970). É um movimento dinâmico. O objeto aparece como índice de sua constituição transcendental que nada mais é que o fruto de uma intencionalidade constituinte.

Rev. Filos., Aurora, Curitiba, v. 22, n. 31, p. 391-408, jul./dez. 2010 
de pensar; de uma paixão de pensar. As condições de uma verdadeira critica e de uma verdadeira criação são as mesmas: destruição de um pensamento que pressupõe a si próprio, gênese do ato de pensar no próprio pensamento (DELEUZE, 1988, p. 203).

Talvez, no intensivo como tal, como elemento diferencial, independente de qualquer relação com "objeto ou sujeito", mas que se implica diretamente no sistema em que ela se efetiva e de alguma maneira dramatiza a existência. À tese de que "toda consciência é consciência de algo", Deleuze afirma que "há no mundo alguma coisa que força a pensar" (DELEUZE, 1988, p. 231). Mas num outro aspecto, tanto em Deleuze quanto em Husserl encontraremos a ideia de um "encontro fundamental". Ao afirmar que "alguma coisa" nos força a pensar, esse "algo" é o objeto provocador de uma violência ao pensamento.

Aquilo que só pode ser sentido (o sentiendum ou o ser do sensível) sensibiliza a alma, torna-a "perplexa", isto é, força-a a colocar um problema, como se o objeto do encontro, o signo, fosse portador de problema - como se ele suscitasse problema (DELEUZE, 1988, p. 204).

O "ser" do sensível que tanto inspiraria Deleuze e que passa despercebido à recognição. Esse "ser insensível” do sensível não poderia ser aquilo que é verdadeiramente apreendido quando fazemos a afirmação de que "toda consciência é consciência de algo"? Basta lembrar que em ambos há uma critica constante ao empirismo e a como ele é apresentado. Deleuze, em sua obra intitulada Lógica do sentido (2000), nos mostra o seu grande interesse pelo trabalho de Edmund Husserl. Graças a esse interesse, arriscamos afirmar que aquilo que ele chama de "ser do sensível" se aproxima do conceito de noema em Husserl. O noema também se apresenta como portador de um problema e provocador de um encontro. Para Deleuze, há algo que escapa a essa sensibilidade. "Não é um ser sensível, mas o ser do sensível. Não é o dado, mas aquilo pelo qual o dado é dado" (DELEUZE, 1988, p. 203). É justamente esse "algo da ordem do insensível" que força a pensar, que obriga violentamente ao pensamento. Sendo assim, avançamos o problema: podemos reduzir o mundo, os estados de coisas, num conteúdo intencional? É a esta verdade da filosofia fenomenológica que direcionamos as interrogações deleuzianas e seu sentimento de estranheza em relação à constituição de uma verdade no mundo. Há algo que sempre foge, "cada faculdade saiu dos eixos. Mas o que são os eixos 
a não ser a forma do senso comum que fazia com que todas as faculdades girassem e convergissem?" (DELEUZE, 1988, p. 205).

Mas existe no pensamento de Husserl um terreno difícil de percorrer. Essas dificuldades são apresentadas na Primeira Meditação: "Rumo ao ego transcendental", quando Husserl insiste na ideia de uma ciência verdadeira e invariante que tenha no seu "domínio originário" a subjetividade transcendental. Nela, há um ego como fundamento e sustentação do sentido. Uma consciência que tem na intenção o seu grande momento. É na consciência transcendental que se encontrará a resposta para a questão das "verdades primeiras e apodícticas". Mas quando Husserl fala de sua dúvida entre uma "evidência concebível e a possibilidade de percebê-la como apodíctica", mesmo que posteriormente ele se refugie no "ego transcendental", não deixará de admitir uma peculiaridade que invade o conhecimento transcendental das "coisas em-si mesmas": o objeto enquanto portador de uma realidade como horizonte aberto. Essa exposição encontra-se na Primeira Meditação, tópico 9: "Alcance da evidência apodíctica do eu sou".

[...] Mas, nessa presença, o objeto possui, para o sujeito que percebe, conjunto aberto e infinito de possibilidades indeterminadas que não são, elas próprias, atualmente percebidas. Esse espectro, esse "horizonte" é tal que implica a possibilidade de ser determinado em e por experiências possíveis. De maneira igualmente análoga, a certeza apodíctica da experiência transcendental percebe o meu eu sou transcendental como capaz de implicar a indeterminação de um horizonte aberto. A realidade do domínio de conhecimento original está, portanto, absolutamente estabelecida, mas também sua limitação, que exclui tudo aquilo que ainda não se apresentou, "ele próprio", a descoberta na evidência viva do eu sou. [...] "[...] Em que medida o eu transcendental pode enganar-se a respeito de si próprio, e até onde se estendem, apesar dessa ilusão possível, os dados absolutos e indubitáveis? Por outro lado, ao instituirmos o ego transcendental - e mesmo se negligenciarmos por enquanto os problemas dificeis relativos à apodicticidade - chegamos a um ponto perigoso (HUSSERL, 2001, p. 40-41, grifos nossos).

Esse problema é o que mais contribuirá para aproximar Deleuze e Husserl. Mesmo não sendo indiferente ao papel de significante dado ao ego transcendental, o terreno do conhecimento, por vezes, se apresenta movediço: há uma limitação. É justamente ao admitir o perigo que proporciona um objeto em sua indeterminação, que Deleuze se encanta com Husserl. O autor, que 
raramente é observado em Diferença e repetição, na obra Lógica do sentido experimenta um tipo de "redenção" em Deleuze, se apresentando como uma "sombra fantasma".

\section{Entre Deleuze e Husserl: uma aproximação possível e os limites da simpatia}

O que mais impressiona Deleuze ao tratar do pensamento de Husserl é quando este admite um grau de "selvageria" que percorre os estados de coisas. Já na Terceira Série: Da proposição, no Lógica do sentido, Deleuze direciona suas questões para a problemática do perigo que representariam "esses limites" dados ao ego transcendental por Husserl. O que se passará a partir de uma aproximação pode causar grande surpresa, a ponto de afirmarmos que Husserl se transforma, na obra Lógica do sentido, num dos principais interlocutores para Deleuze. Para Deleuze, na série Da Proposição só se é possivel designar sob o prisma de uma representação, visto que ela conjura os critérios do verdadeiro e do falso a partir de um plano de evidência. Há uma função de preenchimento destinada ao objeto designado (Husserl utiliza a mesma terminologia). A proposição de designação deve ter como referente outra dimensão da proposição, que Deleuze chama de manifestação, correspondente ao ego transcendental husserliano, exigência maior enquanto "manifestante de base" - sujeito que fala e que exprime. O que observamos é que se apresentam, segundo Deleuze, problemas para que as "condições de verdade" sejam estabelecidas, segundo os critérios da fenomenologia, que buscaria naquilo que Deleuze chama de Proposição de Significação os conceitos universais e gerais para fundamentar as condições de verdade.

Para fugir dos riscos de uma "teoria do conhecimento" presa a uma dimensão meramente "gnosiológica" (de mera adequação entre sujeito e objeto), Husserl procurou exaustivamente "neutralizar" determinada dimensão do objeto, abrindo o campo de compreensão para uma região ontológica em que sujeito e coisa (objeto) estão distantes e são assimétricos. Há, sim, um estilo de comunidade ontológica, em que todo o interesse da relação será entre os polos ontologicamente constituídos. Em Husserl, teríamos a dimensão pura do objeto - região noemática - uma camada "ideal", mas com sentido, tal qual pensava Deleuze. Para Husserl, o noema não seria uma mera imagem mental da duplicação da realidade. Ora, se Husserl novamente se afasta de Deleuze ao dizer que o sentido seria diretamente implicado numa consciência 
constituinte, ou algo do tipo como uma "proposição de manifestação", não seria o mesmo Deleuze quem nos ajudaria ao afirmar que "todo o sentido (noema) não pode existir 'fora da proposição' que o exprime"? Sendo assim, quando Husserl afirma uma dependência do sentido à consciência constituinte, isso significaria que o sentido-noema não pode existir fora da proposição, isto é, "o expresso não existe fora de sua expressão".

Quando Husserl se interroga, por exemplo, sobre o "noema perceptivo" ou o "sentido da percepção", ele o distingue ao mesmo tempo do objeto físico, do vivido psicológico, das representações mentais e dos conceitos lógicos. Ele o apresenta como um impassível, um incorporal, sem existência física, nem mental, que não age nem padece, puro resultado, pura "aparência": a árvore real (o designado) pode queimar ser sujeito ou objeto de ação, entrar em misturas, não o noema da árvore. Há muitos noemas ou sentidos para um só e mesmo designado: estrela da noite e estrela da manhã são dois noemas, isto é, duas maneiras pelas quais um mesmo designado se apresenta em expressões. Mas, nestas condições, quando Husserl diz que o noema é o percebido tal como aparece em uma apresentação, o "percebido como tal" ou a aparência, não devemos compreender que se trata de um dado sensível ou de uma qualidade, mas ao contrário, de uma unidade ideal objetiva como correlato intencional do ato de percepção. Um noema qualquer não é dado em uma percepção (nem em uma lembrança, nem em uma imagem), ele tem um estatuto completamente diferente que consiste em não existir fora da proposição que o exprime, proposição perceptiva, imaginativa, de lembrança ou de representação (DELEUZE, 2000, p. 21-22).

Enfim, naquilo que poderia enfraquecer o pensamento husserliano é que Deleuze encontra a sua relevância e força: onde se encontra tudo aquilo que não se apresentou? Que limite é este que faz Husserl experimentar o perigo do incondicionado?

Por um momento, Husserl nos apresenta uma teoria do mundo ou dos estados de coisas que se mistura enquanto elemento constitutivo do sujeito. Essa mistura apresenta-se como um "defeito" na instauração da condição da verdade, dado que condicionado e condição são imbricados. Na obra Expérience et Jugement, Husserl, no §9, fala sobre essa "mistura" e sobre a correspondência entre duas lógicas e gêneses.

Na medida onde nós nos interrogamos sobre a gênese daquilo que é considerado como lógica, nós temos ao contrário, mostrado de fato sua gênese 
numa generalidade universal, porque é precisamente a suposição tácita dessa lógica tradicional que tudo o que pode entrar como substratos nos seus julgamentos pertencem à unidade de nossa experiência e, em seguida, deve ser levada novamente a um tipo fundamental: àquele do ser como ser-nomundo, e que nós temos aqui o estilo universal e os quadros invariantes no interior dos quais tudo deve ser encontrado (HUSSERL, 1970, p. 46-47).

Tanto Deleuze quanto Husserl, ao procurarem um "termo real" que escape às aporias proporcionadas ao se pensar as condições do pensamento, encontram a proposição do "sentido" (reside aqui a simpatia que os aproxima). Mostrando-se mais uma vez original ao pensar a história da filosofia, Deleuze associa a ideia de sentido à ideia de expresso em Husserl. E este expresso (noema) em Husserl é libertado do objeto empírico. É o objeto puro. E isso não significa ficar preso nas armadilhas da linguagem. Entendemos que o problema é mais de uma natureza ontológica, do que de "atributos ou qualidades" designáveis, como ficou fortemente marcada a primeira fase de Husserl pela obra Investigações lógicas (1900-1901). Segundo Deleuze (2000, p. 22),

do verde como cor sensível ou qualidade, distinguimos o "verdejar" como por noemática ou atributo. A árvore verdeja, não é isto, finalmente, o sentido da cor da árvore e a árvore arvorifica, seu sentido global? O noema será outra coisa além de um acontecimento puro, o acontecimento de árvore (embora Husserl não fale assim, por razões terminológicas)? E o que ele chama de aparência, que é senão um efeito de superfície? Entre os noemas de um mesmo objeto ou mesmo de objetos diferentes se elaboram laços complexos análogos aos que a dialética estóica estabelece entre os acontecimentos. Seria a fenomenologia esta ciência rigorosa dos efeitos de superfície?

Estas longas mas necessárias notas nos levam a perguntar sobre que estranhos segredos perpassam os corpos? Seria a fenomenologia uma ciência que se preocuparia exclusivamente em descrever os conteúdos que aparecem à consciência? Ou também discorreria sobre os objetos que não podem jamais se agrupar na unidade de uma síntese de identidade? A interrogação na referência anterior seria, desde já, levantada por Husserl em sua Terceira Meditação, § 29. Neste tópico, Husserl analisa e discorre a respeito do objeto e a distinção de suas estruturas no seio das multiplicidades da consciência, levando-se em consideração, as dificuldades próprias de buscar "todo ser real e sua verdade", numa evidência que ainda não é preenchida pela intuição. Husserl (2000) afirma que 
será o caso, para nós, não de realizar essa evidência de fato - para todos os objetos reais isso seria uma meta desprovida de sentido, pois, como dissemos, uma evidência empírica absoluta é uma "idéia" - mas elucidar (explicitar) sua estrutura essencial, assim como as estruturas essenciais das dimensões de infinidade que constituem e compõem de maneira sistemática sua síntese ideal infinita. É uma tarefa fantástica, mas bem determinada. Consiste no estudo da constituição transcendental da objetividade real (HUSSERL, 2000, p. 79-80, grifo nosso).

Husserl chama de tarefa "fantástica" o estudo da constituição transcendental da objetividade real. Não seria este propósito que Deleuze chamou de "aliquid"? O limite-fronteira entre as proposições de designação, manifestação e significação e os estados de coisas? "Alguma coisa" que não é limitada na dimensão espaço-temporal. Um tipo de sentido-acontecimento, já que Husserl, tanto quanto Deleuze, não acredita na possibilidade de uma "resposta" proveniente de um rasteiro (ou vulgar) empirismo?

Quando Husserl fala de uma "limitação" do ego transcendental e que é um momento perigoso em sua trajetória de instituir uma subjetividade transcendental constituinte, não seria o mesmo que dizer que "aquilo" que se apresenta num horizonte de indeterminabilidade dos estados de coisas, dos objetos, é justamente o que escapa de uma determinação lógica ou das proposições de designação ou significação, como afirmaria Deleuze? Neste sentido, haveria em Husserl a abertura para acreditarmos num tipo de região que não pudesse ser "designável" e que não possuísse um termo real para fundamentar uma ciência. Talvez possamos afirmar que, no itinerário de sua obra, os problemas constitutivos do "mundo da vida" o persigam até o fim. ${ }^{6}$

6 Neste caso, ressaltamos o texto de Ernildo Stein que contribui para o entendimento de algumas questões que estamos provocando. A obra $A$ caminho de uma fundamentação pós-metafísica (1997) faz um belo esclarecimento de alguns conceitos husserlianos, em especial o capítulo "O conceito de mundo vivido como fundamento em Husserl". Vejamos o que Stein diz e que ajuda bastante e de alguma maneira corrobora neste momento do trabalho: "Husserl com a palavra Lebenswelt queria procurar um lugar onde houvesse uma evidência não produzida pela redução transcendental: o mundo da vida, essa evidência irrecusável que todos temos, mas da qual não conseguimos falar porque ela não é objeto. Ela é posta como o não-lugar do qual partem todos os lugares ou onde tudo tem lugar. Essa opção de Husserl em definir esse campo revelou-se com o seu grande achado, mas que ao mesmo tempo o pôs em crise [...]”. “[...] Nós poderíamos fazer variações livres sobre esse termo, mas em nenhum momento escaparia o que Husserl disse ao ter criado esse lugar que remete a um horizonte, o qual no dia em que o tratarmos como um lugar definido passa a ser um não-lugar” (STEIN, 1997, p. 120).

Rev. Filos., Aurora, Curitiba, v. 22, n. 31, p. 391-408, jul./dez. 2010 
Mas a simpatia de Deleuze por Husserl encontra um dos limites extremos quando a questão é a crença na ideia de uma série originária. Na Sexta Série do Lógica do sentido, intitulada "Sobre a colocação em séries", há uma maneira de apresentar a distribuição das séries:

Há pois um duplo deslizamento de uma série sobre a outra ou sob a outra, que as constitui ambas em perpétuo desequilíbrio uma com relação à outra. Em segundo lugar, este desequilíbrio deve, ele mesmo, ser orientado: o fato é que uma das duas séries, precisamente a que é determinada como significante, apresenta um excesso sobre outra; há sempre um excesso de significante que se embaralha. Finalmente, o ponto mais importante, que assegura o deslocamento relativo das duas séries e o excesso de uma sobre a outra, é uma instância muito especial e paradoxal que não se deixa reduzir a nenhum termo das séries, a nenhuma relação entre estes termos (DELEUZE, 2000, p. 42-43, grifo nosso).

Para Deleuze, Husserl comete um equívoco quando busca uma nova forma de síntese ou gênese tomando como referência a situação do sujeito dando a este o caráter de totalidade. "A todo objeto "que existe verdadeiramente' corresponde por princípio (no a priori da generalidade incondicionada das essências) a idéia de uma consciência possível na qual o próprio objeto pode ser tomado de maneira originária e, portanto, perfeitamente adequada" (HUSSERL, 1950, p. 478 apud DELEUZE, 2000, p. 100).

Ocorre que Husserl pensa a gênese, não a partir de uma instância necessariamente "paradoxal" e não "identificável" apropriadamente falando (faltando a sua própria identidade como a sua origem), mas ao contrário a partir de uma faculdade originária de senso comum encarregada de dar conta da identidade do objeto qualquer e mesmo de uma faculdade do bom senso encarregada de dar conta do processo de identificação de todos os objetos quaisquer ao infinito (DELEUZE, 2000, p. 100).

\section{Considerações finais}

Se Husserl trata em seu percurso filosófico da "ideia de duas séries" heterogêneas e da batalha pela sua conciliação, noese e noema, isso nada mais será para Deleuze do que o propósito de um regresso, a busca por um ponto adequado e não aleatório no qual pudesse se ancorar todo o princípio. Para 
Deleuze, o sentido dos objetos sendo derivados de um eu como manifestação empobrece a própria noção de transcendental que não se limita à busca de identidades e semelhanças dos objetos no mundo da consciência. Diferentemente, para Deleuze, a ideia de um campo transcendental sem sujeito nos remete à noção de singularidade e impessoalidade. Uma imanência absoluta que não necessita de nada que a justifique. Como disse Deleuze (1997) num último texto, Imanência: uma vida ${ }^{7}$ falamos não de um sujeito, mas de modos de individuação ou hecceidades, de planos de existência que não se dão mais a partir de uma consciência totalizante, unificada e iluminada por um cogito.

\section{Referências}

BEAUliEU, A. Gilles Deleuze et la phenomenologie. Paris: J. Vrin, 2004.

DELEUZE, G. Diferença e repetição. Tradução de Luiz Orlandi e Roberto Machado. Rio de Janeiro: Graal, 1988.

DELEUZE, G. A imanência: uma vida. In: VASCONCELLOS, J.; FRAGOSO, M. A. da R. (Org.). Gilles Deleuze: imagens de um filósofo da imanência. Londrina: UEL, 1997. p. 15-20.

DELEUZE, G. Lógica do sentido. Tradução de Luiz Roberto Salinas Fortes. São Paulo: Perspectiva, 2000.

DELEUZE, G.; GUATTARI, F. O que é a Filosofia? Tradução de Bento Prado Júnior e Alberto Alonso Muñoz. Rio de Janeiro: Edições 34, 1992.

GIL, J. Prefácio. Tradução Margarida Vale de Gato. In: DELEUZE, G. Diferença e repetição. Tradução de Luiz Orlandi e Roberto Machado. Lisboa: Relógio d'Água, 2000. p. 6 .

HUSSERL, E. A filosofia como ciência do rigor. Tradução de Albin Beau. Coimbra: Atlântida, [19--?].

7 Este foi o último texto escrito por Deleuze e que foi publicado em um número especial dedicado a ele na revista Philosophie, n. 47, das Les Editions de Minuit, Paris, setembro de 1995. Utilizaremos a tradução feita por Jorge Vasconcellos, Hércules Quintanilha e André Martins, publicada no livro Gilles Deleuze: imagens de um filósofo da imanência. UEL: Londrina, 1997. p. 15-20. 
HUSSERL, E. Idées directrices pour une phenomenologie et une philosophie phénoménologique pures. Tradução de De l'allemand par Paul Ricoeur. Paris: Gallimard, 1950.

HUSSERL, E. Expérience et jugement. Paris: PUF, 1970.

HUSSERL, E. A idéia de fenomenologia. Tradução de Artur Mourão. Lisboa: Edições 70, 1989.

HUSSERL, E. Meditações cartesianas: introdução à fenomenologia. Tradução de Frank de Oliveira. São Paulo: Madras, 2001.

HUSSERL, E. Idéias para uma fenomenologia pura e para uma filosofia fenomenológica. Tradução de Marcio Suzuki. Aparecida, SP: Idéias \& Letras, 2006.

MARTINEZ, F. J.Échos husserliens dans l'oeuvre de G. Deleuze. In: VERSTRAETEN, P.; STENGERS, I. (Org.). Gilles Deleuze. Paris: J. Vrin, 1998. p. 105-117.

SANTOS, J. H. Do empirismo à fenomenologia: a crítica antipsicologista de Husserl e a idéia da lógica pura. Braga: Livraria Cruz, 1973.

STEIN, E. A intuição categorial em Husserl: o segredo da fenomenologia; o conceito de mundo vivido como fundamento em Husserl. In: STEIN, E. A caminho de uma fundamentação pós-metafísica. Porto Alegre: EDIPUCRS, 1997. p. 91-100; 111-131.

Recebido: $23 / 07 / 2010$

Received: 07/23/2010

Aprovado: 06/09/2010

Approved: 09/06/2010 